\title{
Ignition dynamics in an annular combustor for liquid spray and premixed gaseous injection
}

\author{
K. Prieur ${ }^{\mathrm{a}, \mathrm{b}, *}$, D. Durox ${ }^{\mathrm{a}}$, J. Beaunier ${ }^{\mathrm{a}}$, T. Schuller ${ }^{\mathrm{a}}$, S. Candel $^{\mathrm{a}}$ \\ ${ }^{a}$ Laboratoire EM2C, CNRS, CentraleSupélec, Université Paris-Saclay, Grande voie des Vignes, 92295 Châtenay-Malabry cedex, France \\ ${ }^{b}$ Safran Tech, E\&P, Rue des Jeunes Bois, Châteaufort, CS 80112, 78772 Magny-Les-Hameaux, France
}

\begin{abstract}
Ignition is of importance in many combustion applications and raises fundamental and practical issues. The lightround process corresponding to the flame spreading phase in the ignition of annular combustors is examined in this article by performing experiments in a model scale configuration "MICCA-Spray". This system features 16 swirling injectors each comprising a hollow cone pressurized injector. Experiments are carried out with premixed gases as well as n-heptane and dodecane sprays. The flow, spray and flame are first characterized in a single injector configuration. Propagation from the initial kernel created by a spark plug is then observed using high speed light emission imaging. This provides flame structures at various times during the process and gives access to the time delays for flame merging. With n-heptane and dodecane fuel injection, it is found that the light-round process is similar to the one observed under fully premixed propane/air experiments but the duration of the process is augmented especially for the less volatile fuel. It is also confirmed that the delay is notably influenced by thermal conditions prevailing in the chamber at the moment of ignition, injection process and fuel composition. Making use of a flamelet like model of the combustion process, the relative changes in light-round time delay are found to be, to the first order, proportional to the relative changes in laminar burning velocity induced by the fuel spray in the air flow.
\end{abstract}

Keywords: ignition dynamics, light-round, spray, swirling flames, annular combustor

\section{Introduction}

In aircraft engine combustors ignition is critical and deserves considerable attention. Combustion is generally initiated by means of a pair of spark plug igniters, usually diametrically mounted in the chamber. Three stages can be identified in the process: (1) In the first, a spark produced by an electric discharge forms a hot gas core, (2) In the second stage, this kernel increases in volume and reaches an injector unit in its vicinity igniting the material exhausted in this region and establishing an initial flame and (3) In the last stage a flame progresses inside the annular chamber and ignites successive injectors, this propagation ultimately leading to combustion stabilization inside the system. This last phase designated as the "light-round" process is considered in this analysis. At this point it is worth reviewing some of the related references. A variety of topics are covered in previous ignition research. Investigations deal with spark characteristics like the minimum spark energy,

${ }^{*}$ Corresponding author: kevin.prieur@centralesupelec.fr

Preprint submitted to $36^{\text {th }}$ International Symposium on Combustion initial flame kernel size, radical creation for a successful ignition [1-5], gas velocity effects, equivalence ratio, heterogeneity of the flow near the spark gap $[2,6-$ 8], ignition probability and turbulence influence [8-11]. Many studies concern the influence of fuel spray parameters $[2,12]$, but most experiments deal with single injector ignition.

Ignition experiments in multi-burner systems are scarce, until recently. Effects of burner separation on gaseous premixed flame ignition and propagation to neighboring injectors in a linear arrangement of 5 swirling injectors were reported in $[13,14]$. Only a few studies have been carried out in annular combustors under fully premixed or non-premixed conditions [15-17]. It is found that the light-round can be decomposed into five stages and that the delay before flames propagating in clockwise and counterclockwise directions merge is reduced when the injection velocity increases [16]. It is observed that the delay is notably influenced by thermal conditions prevailing in the chamber at the moment of ignition and that it is reduced if the chamber walls are at high temperature.

October 9, 2016 


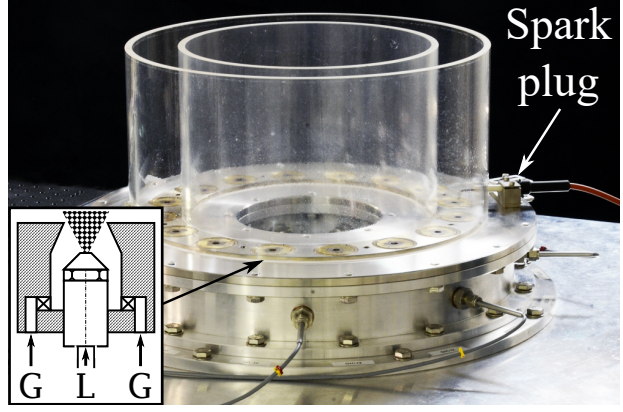

Fig. 1. Photograph of the MICCA-Spray combustion chamber with sixteen liquid injectors and equipped with $200 \mathrm{~mm}$ quartz tubes and a single spark plug. An atomizer is sketched on the bottom left where $\mathrm{G}$ stands for gas and $\mathrm{L}$ for liquid injection channels.

Progress has also been accomplished with the development of simulation tools which have been mainly used to examine ignition processes in single injector configurations. There is however a notable exception [18] reporting a simulation of a full ignition sequence in an annular multiple injector combustor. More recent LES calculations [19-21] have been carried out in parallel with experiments [16] on a fully premixed swirling injector combustor (MICCA). This has led to high fidelity calculations of the light-round sequence observed experimentally.

At present one finds no experiment concerning the light-round in an annular configuration with liquid spray injection. The objective of this article is to provide such data from systematic experiments and to quantify the differences between a premixed ignition and a spray injection ignition in an annular system. Such experiments provide useful information on the process and the data could be effectively used to guide numerical modeling efforts. The study relies on a laboratory scale apparatus designated as MICCA-Spray having multiple spray injectors and an annular geometry in a configuration which reflects in a simplified geometry the situation prevailing in practical combustors.

This setup is described in section 2. Flow and spray are first characterized in a single injector tubular system under cold and hot fire conditions in section 2.1. Some results of systematic light-round in MICCA-Spray are reported in section 3 using high-speed imaging. These data are used to examine effects of operating conditions and in particular consider the influence of fuel state gaseous or liquid- and nature on the light-round delay. A brief interpretation is proposed in section 4.
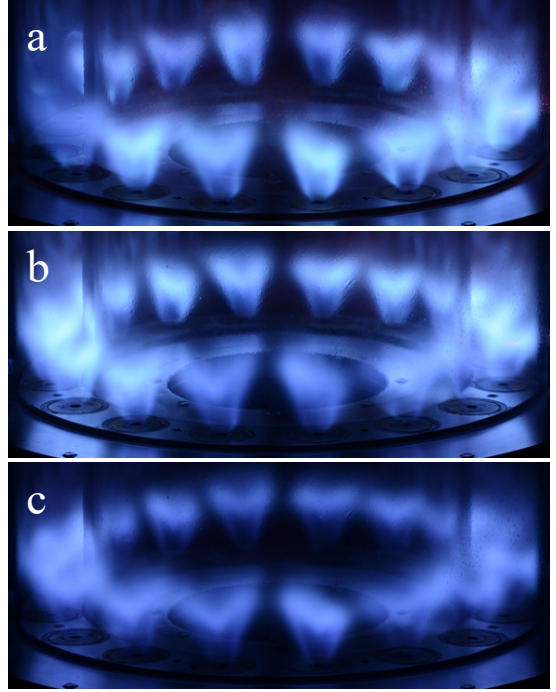

Fig. 2. Direct true-color photograph of the annular chamber with different types of injection : (A) premixed propane and air, (B) n-heptane spray and air, (C) dodecane spray and air. The chamber is under steady operation at a bulk velocity $U_{b}=31.5 \mathrm{~m} \mathrm{~s}^{-1}$, an equivalence ratio $\phi=$ 0.90 and a total power of $\mathcal{P}=80 \mathrm{~kW}$.

\section{Experimental configuration}

The annular system (Fig. 1) comprises a plenum connected to a combustion chamber by 16 swirling injectors that can be supplied with either gaseous or liquid fuels without changing the geometry and the injection system. The swirled flow is injected into the combustion chamber through a convergent end piece with an exit diameter $d=8 \mathrm{~mm}$. Eight channels feed the plenum and, depending on the configuration -gaseous or liquid fuel- these channels deliver a mixture of propane and air or only pure air. Air is injected at ambient temperature. In case of liquid injection, a simplex atomizer is placed after the swirler, $6 \mathrm{~mm}$ in recess with respect to the convergent exhaust (Fig. 1) establishing a hollow cone spray in the chamber.

The plenum is terminated by an annular plate holding the 16 injectors. This serves as the backplane to the chamber formed by two cylindrical concentric quartz tubes. The inner and outer quartz tubes are $200 \mathrm{~mm}$ long and their diameters are respectively 300 and $400 \mathrm{~mm}$. The ignition process is initiated by a spark plug positioned in front of the camera, located on the opposite side of the chamber. Unlike aeronautical combustors, a single igniter is used so the camera can catch the entire dynamics of the light-round process. The igniter is placed $6 \mathrm{~mm}$ from the center of the injector and fixed at the same location in all experiments. A spark is formed every $10 \mathrm{~ms}$ and releases a mean energy of $25 \mathrm{~mJ}$. The 
ignition sequence is recorded by an intensified highspeed CMOS camera APX-i2 comprising $512 \times 512$ pixels with 8-bit resolution. The frame rate and shutter speed are respectively set at $6000 \mathrm{~Hz}$ and $166 \mathrm{~ms}$. The camera amplifier gain remains constant in all experiments.

The MICCA-Spray chamber features stable flames with gaseous and liquid fuels for a wide range of operating conditions. Flame shapes with the different fuels tested are shown in Fig. 2. In the three configurations, the sixteen turbulent flames take a typical "M" shape with no mutual interaction. Whatever the effort made, it was not possible to obtain perfectly symmetric and uniformly balanced injectors due to the small atomizer sizes. Experiments are carried out for a broad range of conditions to compare premixed gaseous propane air injection with liquid spray injection. In the latter case, high and low volatility fuels are compared: n-heptane and dodecane. The vaporization rate of $n$-heptane is $0.056 \mathrm{~mm}^{2} / \mathrm{s}$ in quiescent air at $300 \mathrm{~K}$ [22] and can be doubled when motionless droplets are injected in an airflow at $1 \mathrm{~m} \mathrm{~s}^{-1}[22,23]$. Dodecane can be considered as non-volatile at ambient temperature. It is less volatile as decane which has a low vaporization rate of $0.0021 \mathrm{~mm}^{2} / \mathrm{s}$ in quiescent air [22]. The global equivalence ratio ranges from $\phi=0.7$ to 1.1 . The power of the chamber varies from $\mathcal{P}=65$ to $100 \mathrm{~kW}$ and the bulk velocity is increased from $U_{b}=25$ to $41 \mathrm{~m} \mathrm{~s}^{-1}$. The corresponding Reynolds number based on the injector exit diameter varies from 15,400 to 20,500 .

\subsection{Single injector aerodynamic and spray structures}

It is convenient to use a single injector to characterize the aerodynamic and spray structures with laser optical tools. This setup represents a sector of the MICCASpray annular chamber. The surface section of the single burner chamber is equivalent to the confinement of a flame in MICCA-Spray. The flame in the single burner is similar in shape to those found in the annular chamber (not shown here). The burner is equipped with a $70 \mathrm{~mm}$ diameter and $150 \mathrm{~mm}$ long quartz tube. The length of the quartz tube does not affect the aerodynamic and spray structures. The total power of the single burner is close to $\mathcal{P}=5 \mathrm{~kW}$. A 9-bar pressurized fuel tank supplies the atomizer with n-heptane. An argon-ion laser at $514.5 \mathrm{~nm}$ is used to record horizontal and vertical tomographic slices of the droplet spray under hot fire conditions. In Fig. 3A and B, the horizontal slices respectively correspond to a level $z=10 \mathrm{~mm}$ and $z=2.5 \mathrm{~mm}$ above the backplane (the $z$-axis is along the main air flow direction). The laser slice in Fig. 3A, at the foot of the flame, shows that droplets are still present in the

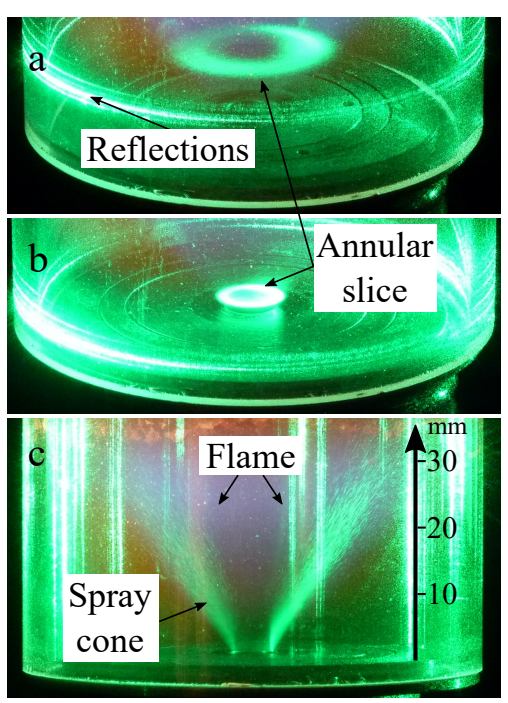

Fig. 3. Horizontal $(A, B)$ and vertical $(C)$ tomographies of the $n$ heptane droplet spray with flame $\left(\phi=0.86, U_{b}=32 \mathrm{~m} \mathrm{~s}^{-1}, \mathcal{P}=\right.$ $4.95 \mathrm{~kW})$. Tomographies A and B correspond to $z=10 \mathrm{~mm}$ and $z$ $=2.5 \mathrm{~mm}$ respectively. An indicative scale is placed in the second image.

combustion zone. One can see in Fig. 3B that the hollow cone seems congruent to the exit of the convergent plate. This indicates that the periphery of the hollow cone generated by the simplex atomizer partially interacts with the injector walls prior to entering the combustion chamber. This airblast effect is present but only affects a small part of the liquid stream. The vertical slice in Fig. $3 \mathrm{C}$ is observed at $\theta=45^{\circ}$ in the forward direction to maximize the Mie scattering signal. In this image, some blue luminosity indicates that the flame develops from 8 to $30 \mathrm{~mm}$ from the chamber backplane. This slice also reveals the persistence of droplets in the burning area confirming the non-premixed character of the flame. The hollow shape of the liquid cone is also visible in all these images.

A Phase Doppler Anemometer (PDA) yields the velocity profiles of the air flow and the n-heptane droplet diameters in the single burner, under cold conditions. Measurements are carried out without confinement to avoid laser beam deflections due to wall wetting. Measurements with confinement under hot fire conditions confirm that this procedure is adequate. Figure 4 displays the three components $\left\{U_{r}, U_{\theta}, U_{z}\right\}$ measured velocity profiles of the air flow obtained at $z=2.5 \mathrm{~mm}$ for nominal injection conditions. No fuel is injected at this stage and LDA measurements are based on seeding oil droplets (diameter $d_{10}<2 \mu \mathrm{m}$ ) giving access to the entire air dynamics. As the liquid loading is low, the spray only weakly interacts with the air flow. Mean data are 


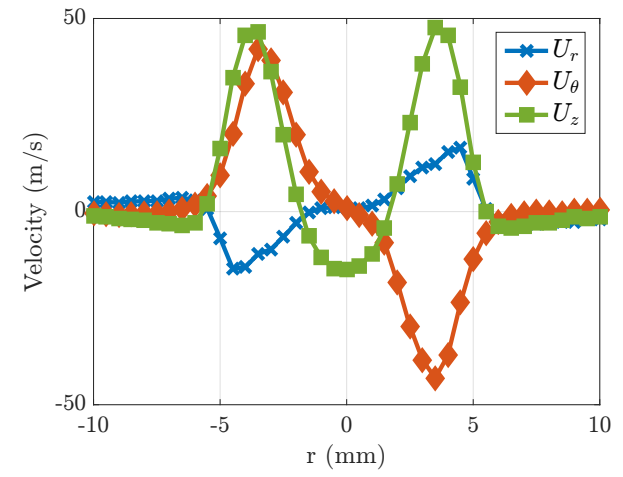

Fig. 4. Mean air velocity profiles $\left\{U_{r}, U_{\theta}, U_{z}\right\}$ measured at $\mathrm{z}=2.5 \mathrm{~mm}$ for a nominal flow rate $\dot{m}_{\text {air }}=1.94 \mathrm{~g} \mathrm{~s}^{-1}$.

shown for 50,000 droplets to ensure good data convergence. High axial velocities are observed with, at peak, $U_{z} \simeq 50 \mathrm{~m} \mathrm{~s}^{-1}$. A strong recirculation zone is present in the center of the chamber. The air flow also features a sizable azimuthal component. The measured velocity profiles used to determine the swirl number provide an experimental value $S=0.68$.

Figure 5 shows the diameter profiles at several levels of the n-heptane droplets injected by the liquid atomizer within the swirling air flow field shown in Fig. 4. At $z=$ $2.5 \mathrm{~mm}$ and $r=5 \mathrm{~mm}$, the mean diameter $d_{10}$ is $\sim 8 \mu \mathrm{m}$. At the same location, the Sauter Mean Diameter (SMD) $d_{32}$ is $\sim 27 \mu \mathrm{m}$. These relatively small diameters confirm the good atomization provided by the liquid fuel injector. One can deduce from measurements at different levels a mean value of the SMD averaged along the radial axis, representing the general droplet population at the top of the swirling jet, $d_{32}=30 \mu \mathrm{m}$. Note that the particular behavior of the SMD in the center of the chamber at $z=2.5 \mathrm{~mm}$ is not found downstream. These measurements might have been altered as they were done just at the exit of the injector, in the recirculation zone, where the droplet number is low.

\section{Light-round experimental data and interpreta- tion}

The light-round processes in the annular chamber are now compared for three fuels : propane (gaseous), nheptane (liquid) and dodecane (liquid). The sequence is characterized by the time delay $\tau_{l}$ corresponding to the duration between the initial growth of the flame kernel around the igniter and the merging point of the two flame branches propagating in the annulus. A strict experimental protocol is used in order to keep a hot con-
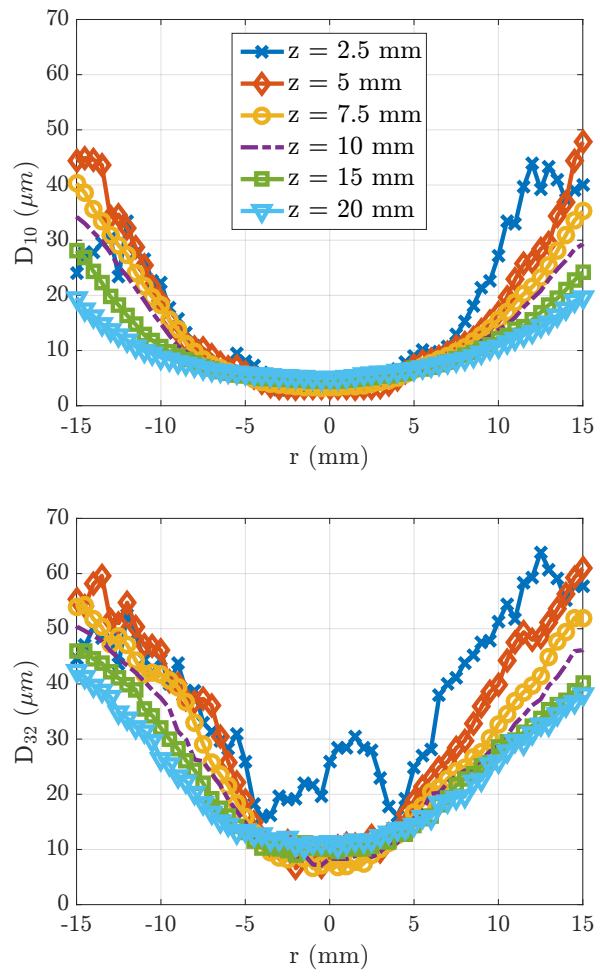

Fig. 5. n-Heptane droplet diameter profiles $\left\{d_{10}, d_{32}\right\}$ in non-reactive case at different altitudes $z$ for a nominal flow rate $\dot{m}_{f u e l}=0.11 \mathrm{~g} \mathrm{~s}^{-1}$ and $\dot{m}_{\text {air }}=1.94 \mathrm{~g} \mathrm{~s}^{-1}$.

stant temperature of the walls between the different experiments :

- The chamber is preheated until stable thermal conditions are reached (thermocouple measurements indicate a stable wall value of $900 \mathrm{~K}$ after $500 \mathrm{~s}$ at $\mathcal{P}=80 \mathrm{~kW})$

- Fuel (gaseous or liquid) is turned off and kept off for 5 seconds to avoid autoignition;

- Fuel injection is turned on for a few seconds until the fuel flow rate is stabilized (this time depends on the flow meter dynamics).

- The high speed camera is triggered and the chamber is ignited using the spark plug;

- When the process is terminated, another can be initiated until the memory of the camera is filled up.

The residence time in the $200 \mathrm{~mm}$-long chamber calculated for the different injection velocities varies from $\tau_{r}=0.3$ to $0.5 \mathrm{~s}$ and one may safely assume that the volume is homogeneously filled with the mixture during the ignition procedure. Several sparks are needed to ignite a small flame kernel near the plug. This time delay defines the spark delay $\tau_{s}$. Depending on the equivalence ratio and on the velocity, $\tau_{s}$ can take from 5 to 

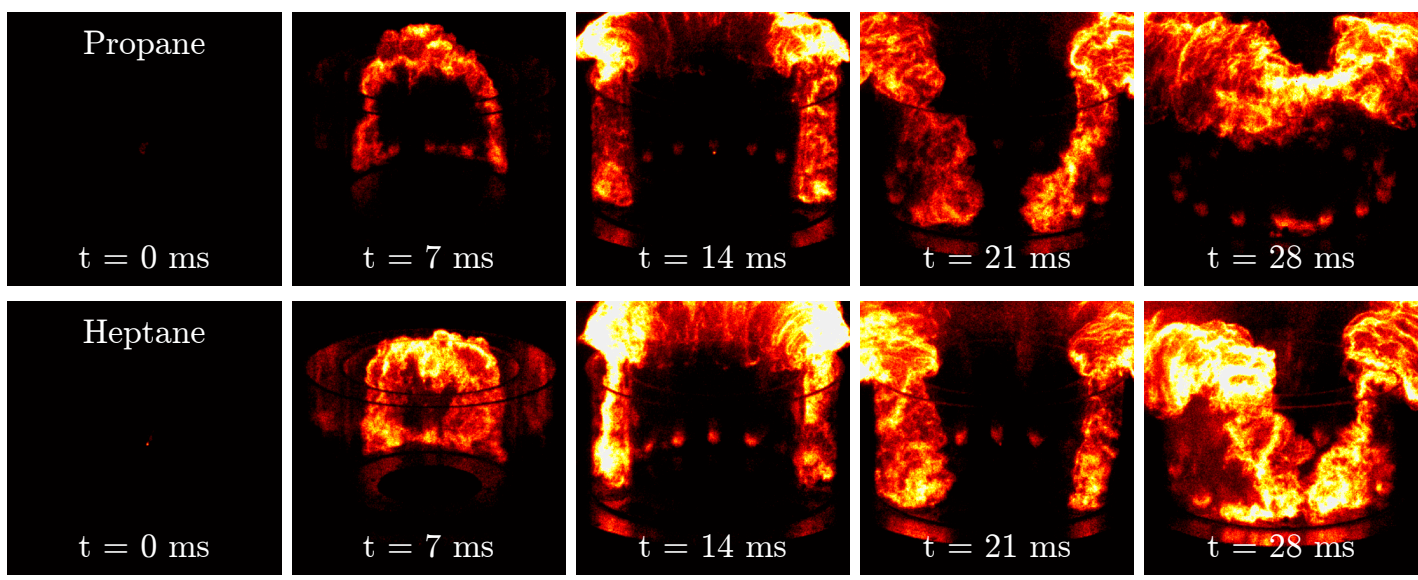

Fig. 6. Light emission during the ignition sequence of propane (top) and n-heptane (bottom) fuels. Yellow corresponds to high light intensity while dark red represents low light emission. Each sequence features equivalent injection conditions : $U_{b}=31.5 \mathrm{~m} \mathrm{~s}^{-1}, \phi=0.90$ and $\mathcal{P}=80 \mathrm{~kW}$.

almost $1000 \mathrm{~ms}$. Spark delays are longer with liquid fuels due to the need to evaporate some fuel before it can burn and probably due to heterogeneous mixtures close to the injector outlet. Also, the number of sparks required increases under lean conditions. This is because the probability of formation of the initial flame kernel is reduced. Several attempts are then needed to ignite. Energy deposited at each spark is small and the heated volume is convected away if no flame kernel is formed and does not alter the light-round process.

Figure 6 shows the full ignition sequences of propane gaseous fuel (top) and n-heptane spray injection (bottom) for identical operating conditions. The same time scales are used for the two sequences in order to compare the evolution of the process. To improve the visualization, each image is plotted on a scale of false colors where yellow corresponds to the highest intensity value, while dark red represents the lowest value in terms of flame radiation intensity. In the first milliseconds, the spark ignites a small flame kernel which determines the initial instant of the light-round time delay $\tau_{l}$. Looking at the n-heptane sequence (bottom of Fig. 6), the flame kernel is first quickly convected between two injectors after the first image $(\sim 0 \mathrm{~ms})$. In the second image, at $t \sim$ $7 \mathrm{~ms}$, once this pocket is ignited, it expands in a spherical way. In the third image, at $t \sim 14 \mathrm{~ms}$, the flame features two vertical symmetric arches igniting the burners one after the other. In the fourth image, at $t \sim 21 \mathrm{~ms}$, when approaching the merging point, the flame velocity decreases due to the compression of unburnt gases upstream the two branches, causing the arches to take back a spherical shape. The branches meet in the fifth image, at $t \sim 28 \mathrm{~ms}$, defining the light-round time delay $\tau_{l}$. For gaseous fuel, this sequence is quite similar and nearly symmetric. For most runs with propane, the merging point is diametrically opposed to the spark plug. Some asymmetry can however be induced by the general swirl direction of rotation. In the case of liquid fuel, the asymmetry can be stronger and partially strengthened by the convected kernel in the first milliseconds. After collapse of the left and right arches, the front is convected upward by the hot gases originating from the burners and steady state is reached as can be seen in the last image of the propane sequence (top of Fig. 6).

A wide range of experimental conditions has been explored to examine the influence of the fuel type on the delay $\tau_{l}$. Three sets of experiments are described below. Note that for premixed propane, the fuel flow rate only slightly increases the bulk velocity $U_{b}(<1.5 \%)$ and this effect may be neglected.

1. Bulk velocity $U_{b}=31 \mathrm{~m} \mathrm{~s}^{-1}$ is kept constant, equivalence ratio varies from $\phi=0.80$ to 1.05 and power $\mathcal{P}$ varies simultaneously from 70 to $90 \mathrm{~kW}$;

2. Equivalence ratio $\phi=0.92$ is kept constant, bulk velocity varies from $U_{b}=25$ to $39 \mathrm{~m} \mathrm{~s}^{-1}$ and power $\mathcal{P}$ varies simultaneously from 65 to $100 \mathrm{~kW}$;

3. Power $\mathcal{P}=84 \mathrm{~kW}$ is kept constant, bulk velocity varies from $U_{b}=27$ to $41 \mathrm{~m} \mathrm{~s}^{-1}$ and equivalence ratio varies simultaneously from $\phi=0.70$ to 1.05 ;

Each point in Fig. 7 corresponds to an ignition sequence with specific injection conditions. Experiments are repeated three to six times to allow accurate delay determinations. The number of experiments is smaller under lean condition due to difficulties in synchronizing the high-speed imaging acquisition and the light-round because the ignition probability is reduced in these conditions. The maximum data scatter is $10 \%$ in Fig. 7A 
(a)

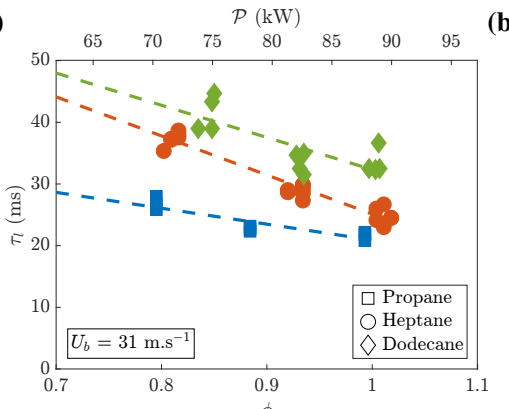

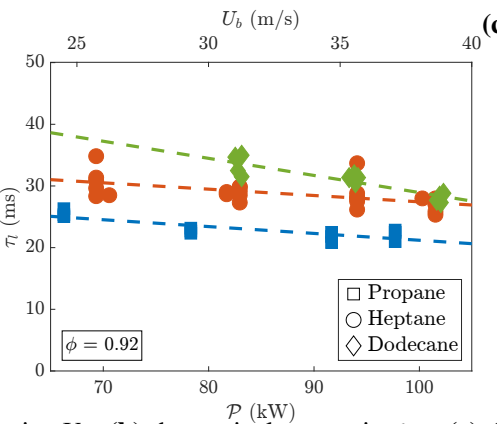

(c)

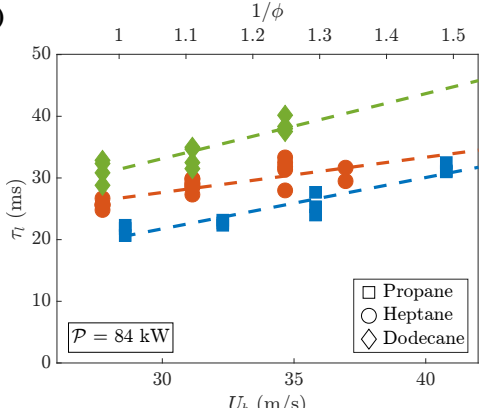

Fig. 7. Light-round delay $\tau_{l}$ when: (a) the bulk velocity $U_{b}$, (b) the equivalence ratio $\phi$ or (c) the power $\mathcal{P}$ is kept constant for multiple fuels : propane (gaseous), n-heptane (liquid spray) and dodecane (liquid spray). Linear fits in dashed lines give the general trend for the different fuels.

and stays relatively small for the other operating points so that three readings are meaningful.

In Fig. 7a, one can see that the general trend is a decrease of $\tau_{l}$ when $\mathcal{P}$ or $\phi$ are increased. For propane fuel, for example, $\tau_{l}$ decreases from $28 \mathrm{~ms}$ at low power to $23 \mathrm{~ms}$ at higher power. The same trend is found for n-heptane and dodecane. Experiments also indicate that when the equivalence ratio rises, the delay is reduced. This corresponds to an increase in the burnt gas temperature and in the laminar burning velocity. Both factors tend to reduce the delay $\tau_{l}$ as discussed in section 4 .

In Fig. $7 \mathrm{~b}$, as $\phi$ is fixed, $\mathcal{P}$ and $U_{b}$ are linearly linked. When the power is increased, more fuel is injected in the chamber so the air flow rate has to be increased to keep a constant equivalence ratio. As a consequence, the quantity of burnt gases increases. The temperature of these burnt gases is constant. As the volumetric expansion of these gases is a key parameter for the propagation of the flame front in the ignition sequence [16], increasing the amount of burnt gases results in a slight decrease of the light-round delay $\tau_{l}$.

In Fig. 7c, as the power is fixed, the equivalence ratio and the burnt gas temperature decreases when the bulk velocity increases. In this case $\tau_{l}$ increases with $U_{b}$ confirming that the burnt gas temperature plays a key role.

Tab. 1. Mean light-round time delay $\tau_{l}$ for propane (gaseous), nheptane (liquid) and dodecane (liquid) fuels for increasing equivalence ratio and power when the bulk velocity $U_{b}=31 \mathrm{~m} \mathrm{~s}^{-1}$ is kept constant. Relative changes $\Delta \tau_{l} / \tau_{l}$ are given in parenthesis.

\begin{tabular}{|c|c|c|}
\hline & $\phi=0.92$ & $\phi=1.0$ \\
& $\mathcal{P}=82 \mathrm{~kW}$ & $\mathcal{P}=89 \mathrm{~kW}$ \\
\hline Propane & $23.5 \mathrm{~ms}$ & $21 \mathrm{~ms}$ \\
n-Heptane & $29 \mathrm{~ms}(+23 \%)$ & $25 \mathrm{~ms}(+19 \%)$ \\
Dodecane & $35.5 \mathrm{~ms}(+51 \%)$ & $32 \mathrm{~ms}(+52 \%)$ \\
\hline
\end{tabular}

Table 1 compares the delay $\tau_{l}$ at two injection conditions for the three fuels when the power is kept constant. The delay $\tau_{l}$ varies from 20 to $40 \mathrm{~ms}$. One finds that $\mathrm{n}$ heptane fuel takes roughly $20 \%$ more time to ignite the chamber than propane fuel while dodecane fuel takes $50 \%$ more time with respect to the premixed propane air case. These relative changes are much greater than the maximum relative scatter indicating that the differences in the light-round delay between the three fuels are meaningful.

\section{Discussion}

Experiments indicate that the delay $\tau_{l}$ is augmented when gaseous injection is replaced by liquid spray injection. This delay is increased further when a lesser amount of liquid fuel is vaporized at the start of the process, i.e. when $n$-heptane is replaced by dodecane. A rough interpretation of these data may be put forward by making use of the theoretical framework developed in [16] where it was shown that flame spreading could be represented by an absolute displacement velocity $\left(\rho_{u} / \rho_{b}\right) S_{d}$ where $\rho_{u} / \rho_{b}$ designates the volumetric expansion effect and $S_{d}$ is a normal displacement velocity in a turbulent combustible mixture which depends on the turbulence level and spray characteristics. In a simplified flamelet-like description of this process one may assume that $S_{d}=\Xi S_{L}^{s p}$ where $\Xi$ is a mean wrinkling factor and $S_{L}^{s p}$ is a laminar burning velocity in a spray/air mixture. These various factors are examined below.

Concerning the ratio $\rho_{u} / \rho_{b}$ for the three fuels, one has to evaluate the adiabatic combustion temperature under the same conditions of overall equivalence ratio and injection temperature. In the present experiments, air and fuel are injected at $T_{u} \simeq 300 \mathrm{~K}$. Estimates can be made at $\phi=1$ with chemical equilibrium calculations. For the three fuels, propane, n-heptane and dodecane, the adiabatic flame temperatures are respectively 2267, 2274 and $2279 \mathrm{~K}$. In these calculations, the heat of vaporization is neglected for n-heptane and dodecane, but this contribution is small (less than 1\%). Thus, the three fu- 
els induce about the same volumetric expansion with a maximum deviation of $1.5 \%$.

Considering now the laminar burning velocities at ambient temperature $T_{u} \simeq 300 \mathrm{~K}$ and $\phi=1$, an experimental value $S_{L}=0.40 \mathrm{~m} \mathrm{~s}^{-1}$ is found both for propane [24] and for pre-vaporized n-heptane [25]. The laminar flame calculations of [26] give $0.41 \mathrm{~m} \mathrm{~s}^{-1}$ for the n-heptane. For dodecane, an extrapolation of numerical results [26] and experimental results [27, 28] gives $\simeq 0.40 \mathrm{~m} \mathrm{~s}^{-1}$ in pre-vaporized conditions. One may thus conclude that the three fuels have about the same laminar burning velocities with less than $2.5 \%$ variations in perfectly premixed conditions.

The information on the wrinkling factor $\Xi$ is at this point more qualitative. Turbulent eddies observed in Fig. 6 during the light-round sequences of the propane/air mixture and the n-heptane spray flame are visually similar. Flame wrinkling is due to fluctuations in the gas flow on the upstream side of the flame front. This agitation is generated by the interaction of the swirling flows coming from the injectors. Given the small droplet size and the low concentration of fuel, the turbulent structures in fresh gases are weakly affected by the spray. Thus the value of $\Xi$ is most probably of the same order of magnitude for the three fuels at the same operating point. Differences observed in flame propagation during light-round are therefore linked to the laminar flame burning velocity in the spray/air mixture. One has now to consider the influence of the presence of the droplet spray on $S_{L}^{s p}$. Even if the spray is quite heterogeneous at the injectors exit, very quickly the droplet cloud becomes more homogeneous in the chamber, and to a first approximation, one can consider that the flame spreads in an uniform medium. It is known from experiments $[12,26,29]$ that $S_{L}^{s p}$ depends on four key parameters, $\phi$ the global equivalence ratio, $\Omega=m_{G F} /\left(m_{G F}+m_{L F}\right)$ the vaporized fuel mass fraction, $m_{G F}$ and $m_{L F}$ respectively correspond to the mass of fuel in gaseous and liquid forms in a volume, $d_{32}$ the SMD and $\lambda$ an effective evaporation constant. For a given global equivalence ratio, $S_{L}^{s p}$ decreases when $\Omega$ is reduced [12]. The smallest value of $S_{L}^{s p}$ is obtained when $\Omega=0$, i.e. in a case without initial fuel evaporation in the mixture. $S_{L}^{s p}$ also decreases when $d_{32}$ increases. Using the framework defined in the beginning of this section, $S_{L}^{s p}$ can be estimated for the operating points presented in Tab. 1 and compared with numerical results given in [26]. As already indicated, the laminar burning velocity for the three fuels is about $0.40 \mathrm{~m} \mathrm{~s}^{-1}$ in pre-vaporized conditions. At $\phi=1$ an increase by $19 \%$ for the mean light-round time delay of the n-heptane flame corresponds to an opposite reduction for $S_{L}^{s p}$. In that case $S_{L}^{s p}=0.34 \mathrm{~m} \mathrm{~s}^{-1}$. From [26], in a n-heptane-air mist with a mean diameter $d_{32}=30 \mu \mathrm{m}$, this velocity is obtained when $\Omega=0.75$, i.e. when $75 \%$ of n-heptane is vaporized in front of the flame. For dodecane, the time delay is increased by $52 \%$ at $\phi=1$ in Tab. 1 . Then $S_{L}^{s p}$ must be of the order of $0.26 \mathrm{~m} \mathrm{~s}^{-1}$ in that case. In contrast to n-heptane, one may consider that there is no evaporation of dodecane at ambient temperature. From [26], a calculation made with a decane-air mist (the decane is close to dodecane) gives a velocity of $0.26 \mathrm{~m} \mathrm{~s}^{-1}$ when the mean droplet size is equal to $30 \mu \mathrm{m}$, which corresponds well to the estimated $d_{32}$ in the mist, at the top of swirling jets in Fig. 5. One may then consider that the relative changes in light-round delay correspond to the relative changes in burning velocities induced by the presence of a volatile or less volatile fuel in the spray.

\section{Conclusions}

The dynamics of the light-round process in an annular chamber equipped with multiple swirling injectors is examined experimentally. The ignition process is specifically considered for premixed gaseous propane air and liquid n-heptane and dodecane injection. Highspeed imaging carried out systematically provides a direct view of the flame as it spreads in the annular chamber enabling the characterization of the light-round delay $\tau_{l}$ for a wide range of experimental conditions and indicating that the shape of the flame during light-round is similar for the three fuels. The data indicate how the time delay evolves as a function of equivalence ratio, power level and injection velocity. In general, premixed gaseous injection yields the shortest delay. For liquid fuel spray injection, the delay is shorter when the fuel is easy to vaporize (n-heptane) and it is the longest for dodecane spray injection. The data can be explained at least qualitatively by making use of correlations established for gaseous mixtures in combination with calculations and experiments on laminar flame propagation in sprays. The present experiments can be interpreted in terms of a propagation speed which mainly depends on the thermal expansion, turbulent flame wrinkling and on laminar burning velocity in the spray reactive mixture.

\section{Acknowledgments}

This work was supported by Safran Tech, by CNRS and by ANR (Timber project ANR14-CE23-0009-01).

\section{References}

[1] D. Ballal, A. Lefebvre, Proc. Combust. Inst. 15 (1974) 14731481. 
[2] A. H. Lefebvre, Gas Turbines Combustion, McGraw Hill, New York, 1983.

[3] M. Champion, B. Deshaies, G. Joulin, K. Kinoshita, Combust. Flame 65 (1986) 319-337.

[4] B. Lewis, G. V. Elbe, Combustion, Flames and Explosions of Gases, Academic Press, New York, third edition, 1987.

[5] D. Bradley, F. K.-K. Lung, Combust. Flame 69 (1987) 71-93.

[6] D. R. Ballal, A. H. Lefebvre, Proceedings of the Royal Society of London. Series A 357 (1977) 163-181.

[7] D. R. Ballal, A. H. Lefebvre, Proceedings of the Royal Society of London. Series A 364 (1978) 277-294

[8] S. F. Ahmed, R. Balachandran, T. Marchione, E. Mastorakos, Combust. Flame 151 (2007) 366-385.

[9] T. Marchione, S. F. Ahmed, E. Mastorakos, Combust. Flame 156 (2009) 166-180.

[10] E. Mastorakos, Prog. En. Combust. Sci. 35 (2009) 57-97.

[11] M. Cordier, A. Vandel, G. Cabot, B. Renou, A. M. Boukhalfa, Combust. Sci. Technol. 185 (2013) 379-407.

[12] D. R. Ballal, A. H. Lefebvre, Proc. Combust. Inst. (1981) 321328.

[13] M. Cordier, A. Vandel, B. Renou, G. Cabot, M. A. Boukhalfa, L. Esclapez, D. Barre, E. Riber, B. Cuenot, L. Gicquel, in: Proceedings of ASME Turbo Expo 2013, GT2013-94681, San Antonio, Texas, USA.

[14] D. Barre, L. Esclapez, M. Cordier, E. Riber, B. Cuenot, G. Staffelbach, B. Renou, A. Vandel, L. Y. M. Gicquel, G. Cabot, Combust. Flame 161 (2014) 2387-2405.

[15] E. Bach, J. Kariuki, J. R. Dawson, E. Mastorakos, H.-J. Bauer, in: AIAA Aerospace Sciences Meeting 2013, 51, Gravepine, Texas, USA.

[16] J. F. Bourgouin, D. Durox, T. Schuller, J. Beaunier, S. Candel, Combust. Flame 160 (2013) 1398-1413.

[17] E. Machover, E. Mastorakos, Experimental Thermal and Fluid Science 73 (2015) 64-70.

[18] M. Boileau, G. Staffelbach, B. Cuenot, T. Poinsot, C. Berat, Combust. Flame 154 (2008) 2-22.

[19] M. Philip, M. Boileau, R. Vicquelin, T. Schmitt, D. Durox, J. F. Bourgouin, S. Candel, Physics of Fluids 26 (2014).

[20] M. Philip, M. Boileau, R. Vicquelin, E. Riber, T. Schmitt, B. Cuenot, D. Durox, S. Candel, Proc. Combust. Inst. 35 (2015) 3159-3166.

[21] M. Philip, M. Boileau, R. Vicquelin, T. Schmitt, D. Durox, J. F. Bourgouin, S. Candel, J. Eng. Gas Turbines Power (ASME) 137 (2014) 031501 (9 pages).

[22] J. Wu, Y. Liu, H. Sheen, Int. J. Heat Mass Transf 44 (2001) 4593-4603.

[23] M. Birouk, I. Gökalp, Prog. Energy Combust. Sci. 32 (2006) 408-423.

[24] C. M. Vagelopoulos, F. N. Egolfopoulos, C. K. Law, Proc. Combust. Inst. 25 (1994) 1341-1347.

[25] S. G. Davis, C. K. Law, Proc. Combust. Inst. 27 (1998) 521-527.

[26] A. Neophytou, E. Mastorakos, Combust. Flame 156 (2009) 1627-1640.

[27] P. Wagner, G. Dugger, J. Am. Chem. Soc. 77 (1955) 227-231.

[28] K. Kumar, C. J. Sung, Combust. Flame 151 (2007) 209-224.

[29] G. D. Myers, A. H. Lefebvre, Combust. Flame 66 (1986) 193210. 